\title{
ARTICLE
}

Chronic myeloproliferative neoplasms

\section{Inhibitory effects of midostaurin and avapritinib on myeloid progenitors derived from patients with KIT D816V positive advanced systemic mastocytosis}

\author{
Johannes Lübke ${ }^{1} \cdot$ Nicole Naumann $^{1} \cdot$ Sebastian Kluger $^{1} \cdot J_{\text {Juliana Schwaab }}{ }^{*}$ Georgia Metzgeroth $^{1} \cdot$ Erica Evans $^{2}$.

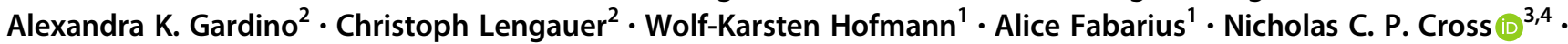 \\ Andreas Reiter $^{1} \cdot$ Mohamad Jawhar $^{1}$
}

Received: 9 January 2019 / Revised: 8 March 2019 / Accepted: 8 March 2019 / Published online: 25 March 2019

(c) The Author(s) 2019. This article is published with open access

\begin{abstract}
Advanced systemic mastocytosis (advSM) is characterized by the presence of an acquired KIT D816V mutation in $>90 \%$ of patients. In the majority of patients, KIT $\mathrm{D} 816 \mathrm{~V}$ is not only detected in mast cells but also in other hematopoietic lineages. We sought to investigate the effects of the KIT-inhibitors midostaurin and avapritinib on single-cell-derived myeloid progenitor cells using granulocyte-macrophage colony-forming-units of patients with KIT D816V positive advSM. Colonies obtained prior to treatment were incubated in vitro with midostaurin $(n=10)$ or avapritinib $(n=11)$ and showed a marked reduction $(\geq 50 \%)$ of $K I T$ D $816 \mathrm{~V}$ positive colonies in $3 / 10(30 \%)$ and $7 / 11(64 \%)$ patient samples, respectively. Three of those $7(43 \%)$ avapritinib responders were resistant to midostaurin in both, in vitro and in vivo. Colonies from four patients with high-risk molecular profile and aggressive clinical course were resistant to both drugs. The in vitro activity of midostaurin strongly correlated with clinical and molecular responses, e.g., relative reduction of KIT D816V allele burden and the proportion of KIT D816V positive colonies obtained after six months midostaurin-treatment in vivo. We conclude that the colony inhibition assay provides useful information for prediction of responses on midostaurin and that avapritinib has a superior in vitro activity compared to midostaurin.
\end{abstract}

\section{Introduction}

Systemic mastocytosis (SM) is a rare hematological neoplasm characterized by clonal expansion and multifocal accumulation of neoplastic mast cells affecting various tissues, predominantly bone marrow, skin, and visceral

These authors contributed equally: Johannes Lübke, Nicole Naumann, Andreas Reiter, Mohamad Jawhar.

Andreas Reiter

andreas.reiter@medma.uni-heidelberg.de

1 Department of Hematology and Oncology, University Medical Centre Mannheim, Mannheim, Germany

2 Blueprint Medicines Corporation, Cambridge, MA, USA

3 Wessex Regional Genetics Laboratory, Salisbury NHS Foundation Trust, Salisbury, UK

4 Faculty of Medicine, University of Southampton, Southampton, UK organs. According to the World Health Organisation (WHO) classification, SM can be subclassified into five categories based on the extent of organ infiltration and mast cell related organ damage (indolent SM [ISM], smoldering SM [SSM], SM with an associated hematologic neoplasm [SM-AHN], aggressive SM [ASM], and mast cell leukemia [MCL]) [1-7]. SM-AHN, ASM, and MCL are collectively referred to as advanced SM (advSM), a poor-prognostic disease with a median overall survival (OS) between three and four years [8-12].

In more than $90 \%$ of advSM patients, somatic gain-offunction point mutations in KIT are detectable, usually the substitution of aspartate (D) to valine (V) at position 816 (KIT D816V) in the kinase domain [13, 14]. A majority of patients with KIT D816V positive advSM harbor additional somatic mutations, most frequently in TET2, SRSF2, ASXL1, RUNX1, JAK2 or N/KRAS [10, 15-18]. In advSM patients, the presence of mutations in SRSF2, ASXL1, and/or RUNXI (S/A/R gene panel) confers a strong adverse impact on phenotype, response to midostaurin, progression to more advSM subtypes, and OS [9, 10, 19]. 
Because of the significance of KIT D816V in the pathogenesis of advSM, targeted drugs against the oncogenic mutation have been developed. Assessing the safety and efficacy of midostaurin (PKC-412) in a multicenter, openlabel, single-arm phase 2 study (NCT00233454), the multikinase/KIT-inhibitor ( $\mathrm{IC}_{50}$ of $2.9 \mathrm{nM}$ ) has demonstrated an overall response rate (ORR; major + partial response) of $60 \%$ per Valent criteria (28\% in a separate post hoc analysis by the European medicines Agency [EMA] according to the International Working Group-Myeloproliferative Neoplasms Research and Treatment [IWG-MRT] \& European Competence Network on Mastocytosis [ECNM] consensus criteria) in advSM patients leading to approval by the US Food and Drug Administration (FDA) and EMA in 2017 [20, 21]. However, validated biomarkers for prediction of response in advSM patients treated with midostaurin are still lacking. Avapritinib (BLU-285), a potent and highly selective KIT $\mathrm{D} 816 \mathrm{~V}$ inhibitor $\left(\mathrm{IC}_{50}\right.$ of $\left.0.27 \mathrm{nM}\right)$, has shown preclinical activity as well as encouraging results in an open-label, dose-escalation in phase I trial evaluating the safety and antineoplastic activity (NCT02561988) [22-24].

The aim of the present study was to establish an amenable in vitro assay to investigate the inhibitory effects of midostaurin and avapritinib on single-cell-derived myeloid progenitor cells using granulocyte-macrophage colonyforming-units (CFU-GM) of patients with KIT D816V advSM and to correlate in vitro colony data with clinical and molecular characteristics at baseline, and response parameters of midostaurin-treated advSM patients in vivo.

\section{Methods}

\section{Patient characteristics and response criteria}

A total of 13 patients with advSM (SM-AHN, $n=11$; ASM, $n=2$ ) were examined. The median age was 67 years (range 48-79). The median OS from time of diagnosis was 33 months (range 13-283). The median bone marrow mast cell infiltration, determined by immunohistochemistry, was $35 \%$ (range 20-70) and median serum tryptase level was $140 \mu \mathrm{g} / \mathrm{L}$ (range 33-739). Additional relevant laboratory, clinical, molecular, and cytogenetic parameters including SM-associated disease characteristics at baseline are summarized in Table 1, and for each individual patient in Tables 2 and 3, respectively. Patients were diagnosed and subtyped according to the WHO 2016 classification [1-7]. Various myeloid AHNs were observed (chronic myelomonocytic leukemia, CMML, $n=3$; myelodysplastic/myeloproliferative neoplasm unclassified, MDS/MPN-U, $n=7$; MPN with eosinophilia, $n=1$ ).

The clinical response to treatment was evaluated by measurable C-findings (excluding ascites and osteolytic lesions) according to modified Valent response criteria as previously described $[3,20]$.

Reference pathologists of the ECNM evaluated all bone marrow biopsies. The study design adhered to the tenets of the Declaration of Helsinki and was approved by the relevant institutional review board of the Medical Faculty of Mannheim, Heidelberg University, as part of the 'German Registry on Disorders of Eosinophils and Mast Cells'. All patients provided written informed consent.

\section{Quantitative assessment of KIT D816V}

Quantitative assessments of the KIT D816V expressed alele burden $(\mathrm{EAB})$ were performed using allele-specific quantitative real-time reverse-transcriptase polymerase chain reaction (qRT-PCR) analysis on RNA/complementary DNA as previously described [14].

\section{Targeted next-generation sequencing (NGS) analysis}

Next-Generation Deep Amplicon Sequencing by 454 FLX amplicon chemistry (Roche, Penzberg, Germany) with consistent detection sensitivity of EAB down to $3 \%$ was performed in all patients to investigate 18 candidate genes as previously described [15]. The customized sequencing panel targeted the hotspot or complete coding regions of the following 18 genes: $A S X L 1, C B L, E T V 6, E Z H 2, I D H 1$, IDH2, JAK2, KRAS, NPM1, NRAS, RUNX1, SETBP1, SF3B1, SRSF2, TET2, TP53, U2AF1, and ZRSR2. The sequential NGS approach is based on library preparation by the Access Array Technology (Fluidigm, San Francisco, CA) and sequencing on the MiSeq Instrument (Illumina, San Diego, CA). Gene mutations were annotated using the reference sequence of the Ensembl Transcript ID (Ensembl release 85: July 2016).

\section{CFU-GM colony assay}

The CFU-GM colony assay is an in vitro assay based on primary bone marrow mononuclear cells using semi-solid methylcellulose $(0.9 \%)$ matrix supplemented with $30 \%$ fetal bovine serum albumin (FBS), 1\% BS albumin, $0.1 \mathrm{M} 2-$ mercaptoethanol and recombinant human GM-CSF (100 ng/ml; MethoCult, StemCell Technologies, Cologne, Germany) in $35 \mathrm{~mm}$ Petri-dishes. The cells $\left(1 \times 10^{5}\right.$ cells in $1 \mathrm{~mL}$ MethoCult) were incubated at $37^{\circ} \mathrm{C}$ in a humidified atmosphere with $5 \% \mathrm{CO}_{2}$ until colonies appeared after 10 14 days. Per colony, 100-300 cells were diluted in phosphate-buffered saline. Based on previous publications and for proof-of-principle, we incubated treatment-naive CFU-GM colonies with $100 \mathrm{nM}$ to $1 \mu \mathrm{M}$ of midostaurin and $22 \mathrm{nM}$ to $90 \mathrm{nM}$ of avapritinib, respectively. Based on the obtained data from these assays (maintenance of colony 
Table 1 Summarized clinical, laboratory, histological, and molecular characteristics of 13 KIT D816V positive advanced systemic mastocytosis patients prior to treatment based on response pattern in single-cell-derived myeloid progenitor cells (CFU-GM colonies, relative reduction of KIT D816V positive colonies), three cohorts were defined: midostaurin + avapritinib responder (cohort \#1), midostaurin non-responder + avapritinibresponder (cohort \#2), and midostaurin + avapritinib non-responder (cohort \#3)

\begin{tabular}{|c|c|c|c|c|}
\hline & Initial & Cohort \#1 & Cohort \#2 & Cohort \#3 \\
\hline Number of patients & 13 & 4 & 3 & 4 \\
\hline Age in years; median (range) & $67(48-79)$ & $58(48-79)$ & $76(75-78)$ & $64(61-67)$ \\
\hline Male, $n(\%)$ & $11(85)$ & $3(75)$ & $3(100)$ & $3(75)$ \\
\hline \multicolumn{5}{|l|}{$\mathrm{C}$-findings ${ }^{\mathrm{a}}$} \\
\hline C-findings, $n$; median (range) & $3(2-4)$ & $3(2-4)$ & $3(2-3)$ & $3(2-4)$ \\
\hline Hemoglobin, g/dL; median (range) & $9.9(7.1-15.0)$ & $10.8(7.1-15.0)$ & $9.4(8.8-12.0)$ & $11.7(9.1-13.9)$ \\
\hline$<10 \mathrm{~g} / \mathrm{dL}, n(\%)$ & $7(54)$ & $2(50)$ & $2(67)$ & $1(25)$ \\
\hline Platelets, $\times 10^{9} / \mathrm{L}$; median (range) & $110(29-426)$ & $190(29-425)$ & $108(80-315)$ & $117(47-426)$ \\
\hline$<100 \times 10^{9} / \mathrm{L}, n(\%)$ & $5(38)$ & $1(25)$ & $1(33)$ & $2(50)$ \\
\hline ANC, $\times 10^{9} / \mathrm{L}$; median (range) & $7.5(1.0-60.0)$ & $8.7(1.7-12.6)$ & $1.3(1.0-6.1)$ & $16.4(6.2-60.6)$ \\
\hline$<1 \times 10^{9} / \mathrm{L}, n(\%)$ & $0(0)$ & $0(0)$ & $0(0)$ & $0(0)$ \\
\hline Alkaline phosphatase, U/L; median (range) & $376(41-707)$ & $204(41-707)$ & $409(303-592)$ & $387(78-632)$ \\
\hline$>130 \mathrm{U} / \mathrm{L}, n(\%)$ & $11(85)$ & $3(75)$ & $3(100)$ & $3(75)$ \\
\hline Albumin level, g/L; median (range) & $34.5(30.0-43.0)$ & $33.1(29.5-40.7)$ & $34.5(33.6-34.5)$ & $34.6(33.6-42.9)$ \\
\hline$<34 \mathrm{~g} / \mathrm{L}, n(\%)$ & $6(46)$ & $2(50)$ & $1(33.3)$ & $2(50)$ \\
\hline Weight loss (>10\% over last 6 months), $n(\%)$ & $8(62)$ & $4(100)$ & $1(33.3)$ & $3(75)$ \\
\hline \multicolumn{5}{|l|}{ B-findings } \\
\hline MC-infiltration in BM biopsy, $\%$, median (range) & $35(20-70)$ & $30(20-50)$ & $50(20-60)$ & $20(20-50)$ \\
\hline Serum tryptase level, $\mu \mathrm{g} / \mathrm{L}$; median (range) & $140(33-739)$ & $104(40-194)$ & $213(128-739)$ & $173(102-225)$ \\
\hline Organomegaly $^{\mathrm{b}}, n(\%)$ & $12(92)$ & $3(75)$ & $3(100)$ & $3(100)$ \\
\hline \multicolumn{5}{|l|}{ Other relevant findings } \\
\hline Leukocytes, $\times 10^{9} / \mathrm{L}$ median (range) & $10.8(2.2-87.0)$ & $12(3.9-15.4)$ & $3.4(2.2-8.9)$ & $20.7(9.1-86.6)$ \\
\hline Monocytes, $\times 10^{9} / \mathrm{L}$ median (range) & $0.8(0.2-6.9)$ & $0.5(0.4-0.6)$ & $0.5(0.3-1)$ & $1.5(0.2-6.9)$ \\
\hline Eosinophils, $\times 10^{9} / \mathrm{L}$ median (range) & $0.4(0.1-3.6)$ & $0.2(0.1-0.3)$ & $0.45(0.1-1.2)$ & $1.5(1.5-1.5)$ \\
\hline $\begin{array}{l}\text { KIT D816V EAB in } \mathrm{PB}, \% \text {, } \\
\text { median (range) }\end{array}$ & $40(18-55)$ & $27(18-47)$ & $41(40-43)$ & $51(40-55)$ \\
\hline Additional mutations besides $K I T \mathrm{D} 816 \mathrm{~V}^{\mathrm{c}}$ & $2(0-5)$ & $1(0-1)$ & $2(2-3)$ & $4(2-5)$ \\
\hline
\end{tabular}

$A N C$ absolute neutrophil count, $B M$ bone marrow, $E A B$ expressed allele burden, $M C$ mast cell, $P B$ peripheral blood

${ }^{a}$ Non-measurable C-findings (e.g., ascites and osteolytic lesions) were excluded

${ }^{b}$ Organomegaly including hepatomegaly, splenomegaly and/or lymphadenopathy

${ }^{\mathrm{c}}$ Additional mutations were detected using targeted sequencing panel to investigate 18 candidate genes

growth in combination with optimum decreasing of $K I T$ D816V positive CFU-GM colonies), we performed our experiments with $600 \mathrm{nM}$ midostaurin and $75 \mathrm{nM}$ avapritinib, respectively [25-27]. Figure 1 outlines an overview on the various colony assays.

\section{Genotyping of CFU-GM}

Whole-genome amplification (REPLI-g, Qiagen, Hilden, Germany) was performed to determine the mutational status of single-cell-derived CFU-GM colonies (mean colonies per assay per patient, $n=15$; range $10-30$, at least 10 colonies were evaluated). Sanger sequencing for mutation validation of KIT D816V and additional mutations was performed after PCR amplification of the relevant region. CFU-GM colonies are expected to be either positive $(50 \%$ in case of heterozygosity, $100 \%$ in case of homozygosity) or negative for any mutation since they are derived from a single myeloid progenitor cell.

\section{Cytogenetic analysis}

For cytogenetic analysis, at least 20 Giemsa-banded bone marrow metaphases cultured for $24 \mathrm{~h}$ and/or $48 \mathrm{~h}$ were prepared as previously described, analyzed by G-/Rbanding technique and interpreted according to the International System for Human Cytogenetic Nomenclature [28, 29]. 


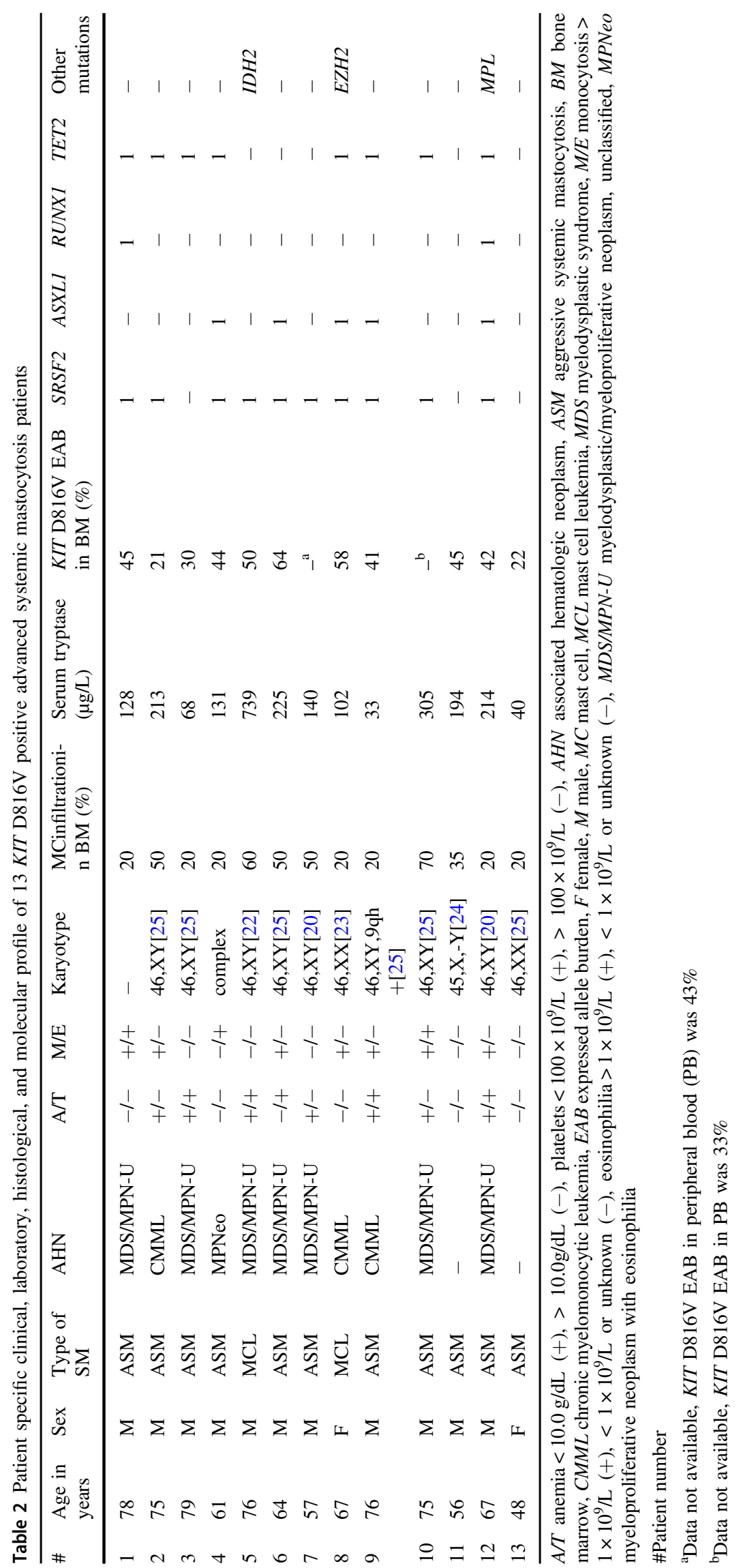


Table 3 Response data in single-cell-derived myeloid progenitor cells (CFU-GM colonies) on midostaurin and avapritinib in 13 KIT D816V positive advanced systemic mastocytosis patients stratified in midostaurin + avapritinib responder (cohort \#1), midostaurin non-responder + avapritinib-responder (cohort \#2), midostaurin + avapritinib non-responder (cohort \#3), and midostaurin responder ${ }^{\mathrm{f}}$ (cohort 4 ) according to relative reduction of KIT D816V positive colonies

\begin{tabular}{|c|c|c|c|c|c|c|c|c|c|}
\hline \# & $\begin{array}{l}\text { Midostaurin } \\
\text { in vivo } \\
\text { (months) }\end{array}$ & $\begin{array}{l}\text { Response }^{a} \\
\text { (Valent } \\
\text { et al.) [3] }\end{array}$ & $\begin{array}{l}\text { KIT D816V } \\
\text { EAB change in } \\
\text { PB on } \\
\text { midostaurin }^{\mathrm{b}}(\%) \\
(\mathrm{Jawhar} \text { et al.) } \\
{[20]}\end{array}$ & $\begin{array}{l}\text { OS from } \\
\text { diagnosis } \\
\text { (months) }\end{array}$ & $\begin{array}{l}\text { Death } \\
\text { (yes/ } \\
\text { no) }\end{array}$ & $\begin{array}{l}\text { KIT D816V } \\
\text { positive } \\
\text { colonies (\%) } \\
\text { (prior to } \\
\text { treatment) }\end{array}$ & $\begin{array}{l}\text { KIT D816V } \\
\text { positive } \\
\text { colonies }(\%) \\
\text { (on } \\
\text { midostaurin } \\
\text { in vivo) }\end{array}$ & $\begin{array}{l}\text { KIT D816V } \\
\text { positive } \\
\text { colonies }(\%) \\
\text { (on } \\
\text { midostaurin }^{\mathrm{in} \text { vitro) }}{ }^{\mathrm{d}}\end{array}$ & $\begin{array}{l}\text { KIT D816V } \\
\text { positive } \\
\text { colonies (\%) } \\
\text { (on } \\
\text { avapritinib }_{\text {in vitro) }}\end{array}$ \\
\hline \multicolumn{10}{|c|}{ Cohort \#1 } \\
\hline 3 & 6 & Yes (MPR) & $82(\downarrow)$ & 42 & No & 100 & 40 & 50 & 0 \\
\hline 7 & 23 & Yes (IR) & $43(\downarrow)$ & 33 & No & 70 & 10 & - & 0 \\
\hline 11 & 13 & Yes (IR) & $72(\uparrow)$ & 133 & No & 80 & 80 & 40 & 10 \\
\hline 13 & 20 & Yes (IR) & $76(\downarrow)$ & 283 & No & 30 & 10 & 10 & 0 \\
\hline \multicolumn{10}{|c|}{ Cohort \#2 } \\
\hline 1 & 3 & No (PD) & 0 & 23 & Yes & 40 & - & 60 & 0 \\
\hline 2 & 3 & No (PD) & - & 22 & Yes & 100 & - & 100 & 0 \\
\hline 5 & 7 & No (PD) & $23(\uparrow)$ & 21 & Yes & 90 & 90 & 90 & 10 \\
\hline \multicolumn{10}{|c|}{ Cohort \#3 } \\
\hline 4 & 7 & No (PD) & $3(\uparrow)$ & 13 & Yes & 90 & 90 & 90 & 70 \\
\hline 6 & 6 & No (PD) & 0 & 15 & Yes & 100 & 100 & 100 & 80 \\
\hline 8 & 7 & No (PD) & $113(\uparrow)$ & 34 & Yes & 100 & 100 & 100 & 100 \\
\hline 12 & 11 & No (PD) & $24(\downarrow)$ & 20 & Yes & 95 & 95 & 90 & 100 \\
\hline \multicolumn{10}{|c|}{ Cohort \#4 } \\
\hline 9 & 31 & Yes (MPR) & $73(\downarrow)$ & 54 & Yes & 90 & 5 & - & - \\
\hline 10 & 22 & Yes (IR) & $62(\downarrow)$ & 46 & Yes & 100 & 10 & - & - \\
\hline
\end{tabular}

$C F U$-GM granulocyte-macrophage colony-forming-unit, $E A B$ expressed allele burden, $I R$ incomplete remission, $M P R$ minor partial response, $O S$ overall survival, $P B$ peripheral blood, $P D$ progressive disease

\#Patient number

${ }^{a}$ Response according to modified Valent response criteria

${ }^{\mathrm{b}}$ KIT D816V EAB change from baseline to month six

${ }^{\mathrm{c}}$ KIT D816V positive colonies from patients on midostaurin at month six

${ }^{\mathrm{d}}$ KIT D816V positive colonies incubated with midostaurin $(600 \mathrm{nM})$ for two weeks

${ }^{\mathrm{e}}$ KIT D816V positive colonies incubated with avapritinib $(75 \mathrm{nM})$ for two weeks

${ }^{\mathrm{f}}$ Data on avapritinib was not available

\section{Statistical analysis}

All statistical analyses considered clinical and laboratory parameters as well as experimental data obtained at the time of midostaurin initiation and after six months treatment (in vivo). Pearson's correlation coefficient was used to compare the change of KIT D816V positive colonies in vitro after two weeks incubation with midostaurin and avapritinib and in vivo after six months midostaurintreatment. The phi coefficient was used to evaluate the association between response according to the mutational status and the KIT D816V EAB in peripheral blood and response to midostaurin in vitro/in vivo. A paired $t$-test was used to compare the relative reduction in the proportion of KIT D816V positive colonies from baseline to in vitrocolonies incubated with midostaurin and avapritinib. OS was defined as the time between diagnosis and the date of death or last contact. $P$ values $<0.05$ (two-sided) were considered significant. GraphPad Prism Software (version 5, GraphPad, La Jolla, CA, USA) and SPSS (version 21.0.0, IBM Cooperation, Armonk, NY) were used for statistical analysis.

\section{Results}

\section{Molecular characteristics prior to treatment}

In addition to KIT $\mathrm{D} 816 \mathrm{~V}$ in all 13 cases, we identified somatic mutations in seven different genes: $\operatorname{SRSF2}(n=10)$, 


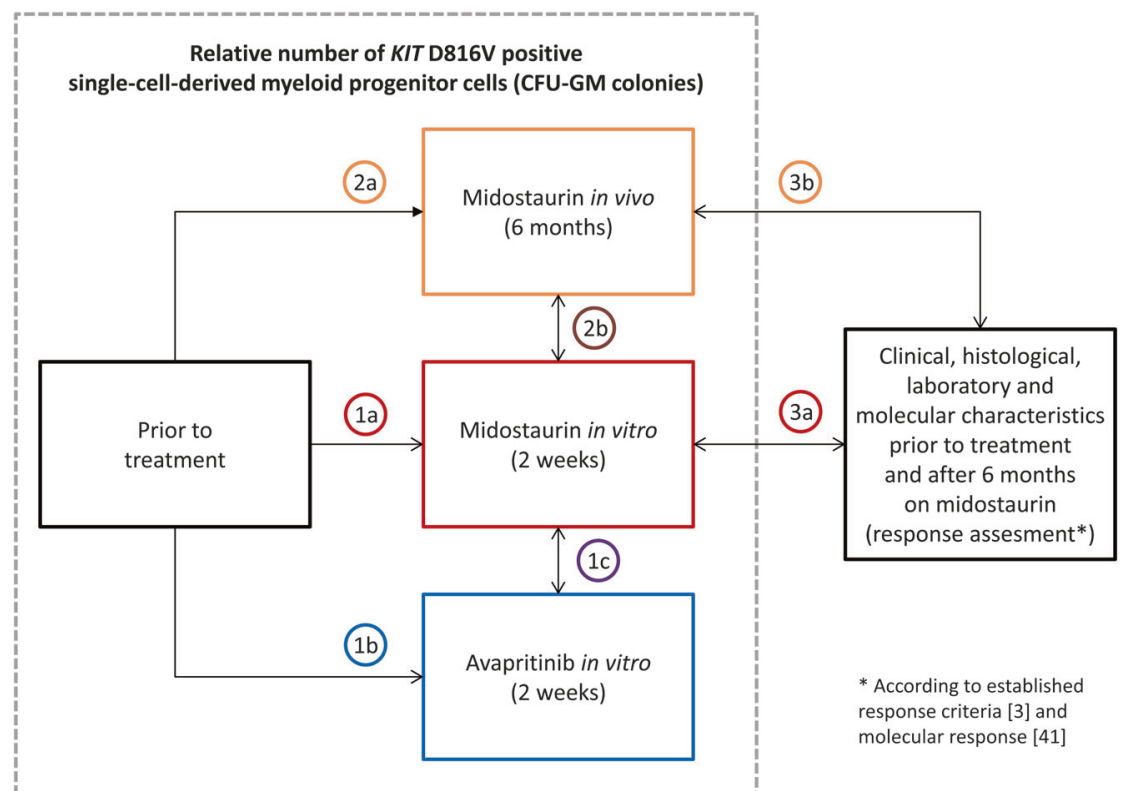

Fig. 1 This figure outlines the design of the study. Comparison (->) or correlation $(<->)$ of the relative reduction of KIT D816V positive single-cell-derived myeloid progenitor cells (CFU-GM colonies) between: prior to treatment versus midostaurin in vitro (1a) or avapritinib in vitro (1b), midostaurin in vitro versus avapritinib in vitro (1c), prior to treatment versus midostaurin in vivo (2a), midostaurin

ASXL1 ( $n=5)$, RUNX1 ( $n=2)$, TET2 $(n=8), I D H 2(n=$ 1), EZH2 $(n=1)$ and MPL $(n=1)$ (Table 2). Eleven of 13 $(85 \%)$ patients showed $1(n=2), 2(n=4), 3(n=3), 4(n$ $=1)$ or $5(n=1)$ additional somatic mutation(s). At least one mutation in the S/A/R gene panel was identified in 10/ 13 cases (77\%). No additional mutations were found in two patients. Two of $13(15 \%)$ patients presented with an aberrant karyotype (Table 2).

\section{In vitro efficacy of midostaurin and avapritinib}

To evaluate the activity of midostaurin and avapritinib against advSM in vitro, we grew CFU-GM colonies from patients in the presence or absence of each drug. For all 13 cases, a median of 90\% (range 30-100) of colonies obtained prior to treatment and grown in the absence of either midostaurin or avaprinitib tested positive for KIT D816V (Table 3). When treated with midostaurin (mean number of colonies per assay and patient, $n=10$, data available in 10 / 13 cases) or avapritinib (mean number of colonies per assay and patient, $n=10$, data available in $11 / 13$ cases), a median of $90 \%$ and $10 \%$ of colonies $(p=0.0102$, Fig. $2 b)$, respectively, were still KIT D816V positive, with $3 / 10$ $(30 \%, \# 3, \# 11, \# 13)$ and $7 / 11$ patients $(64 \%, \# 1, \# 2, \# 3, \# 5$, $\# 7$, \#11, \#13), respectively, showing a $\geq 50 \%$ reduction (responder) of KIT D816V positive colonies (Table 3, Fig. 2a, b). Three of those seven (43\%) avapritinib responders $(\# 1, \# 2, \# 5)$ were resistant to midostaurin while in vivo versus midostaurin in vitro (2b), and patients profile (including clinical, laboratory, histological, and molecular data) and established response assessment $[3,41]$ (after six month midostaurin treatment) versus midostaurin in vitro (3a) and in vivo (3b) assay. CFU-GM granulocyte-macrophage colony-forming-unit

four avapritinib non-responders were also resistant to midostaurin (\#4, \#6, \#8, \#12).

\section{Various response patterns of colonies on midostaurin and avapritinib}

Based on response pattern of colonies (relative reduction of KIT D816V positive colonies), three cohorts were defined: midostaurin and avapritinib responder (cohort $\# 1, n=4)$, midostaurin non-responder and avapritinibresponder (cohort \#2,n=3), and midostaurin or avapritinib non-responder (cohort \#3, $n=4$ ). The comparison between those cohorts reveals no significant differences regarding pure mast cell burden including mast cell bone marrow infiltration $(28,50$ and $20 \%$; $p=$ $0.2909)$ and serum tryptase $(104,213$, and $173 \mu \mathrm{g} / \mathrm{L} ; p=$ 0.1912 ), but significant differences regarding disease burden, median KIT D816V EAB (30, 45, and 51\%; $p=$ $0.0411)$ and number of S/A/R mutation(s) $(0-1, \geq 2$ and $\geq 2 ; p=0.029$ ). No significant differences were seen regarding the various subtypes of advSM or karyotype (Tables 1-3).

\section{Effect of midostaurin and avapritinb on additional somatic mutations}

Colonies (mean colonies per assay per patient, $n=10$ ) were tested for somatic mutations that had previously 
Fig. 2 a Summarizes in vivo and in vitro data regarding the proportion of KIT D $816 \mathrm{~V}$ positive single-cell-derived myeloid progenitor cells (CFUGM colonies) for each patient: a prior to treatment, ${ }^{\mathrm{b}}$ colonies after six months midostaurintreatment in vivo, ${ }^{\mathrm{c}}$ colonies incubated in vitro with midostaurin for two weeks, ${ }^{d}$ colonies incubated in vitro with avapritinib for two weeks. CFUGM, granulocyte-macrophage colony-forming-unit. b Relative reduction in the proportion of KIT D816V positive colonies from baseline (prior to treatment) to in vitro colonies incubated with midostaurin (red) and avapritinib (blue). In patient $\# 7$, midostaurin in vivo data was used (in vitro data not available). Patient order is based on response pattern (responder: at least $50 \%$ relative reduction of KIT D816V positive colonies): midostaurin + avapritinib responder (cohort \#1; patient \#3, \#7, \#11, \#13), midostaurin nonresponder + avapritinibresponder (cohort \#2; patient \#1, \#2, \#5), and midostaurin + avapritinib non-responder (cohort \#3; patient \#4, \#6, \#8, \#12). CFU-GM granulocytemacrophage colony-formingunit
A Prior to treatment ${ }^{\mathrm{a}} \diamond$ Midostaurin (in vivo) ${ }^{\mathrm{b}} \nabla$ Midostaurin (in vitro) $)^{\mathrm{c}} \Delta$ Avapritinib (in vitro) $^{\mathrm{d}}$

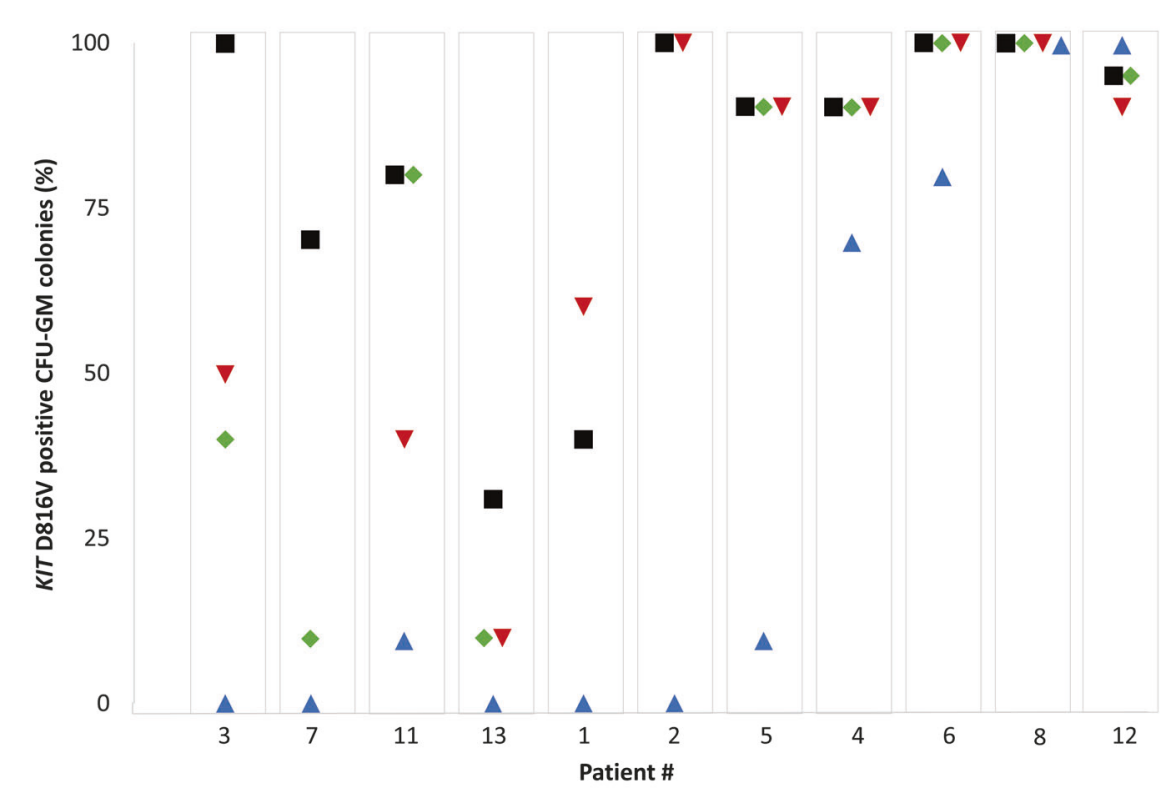

B

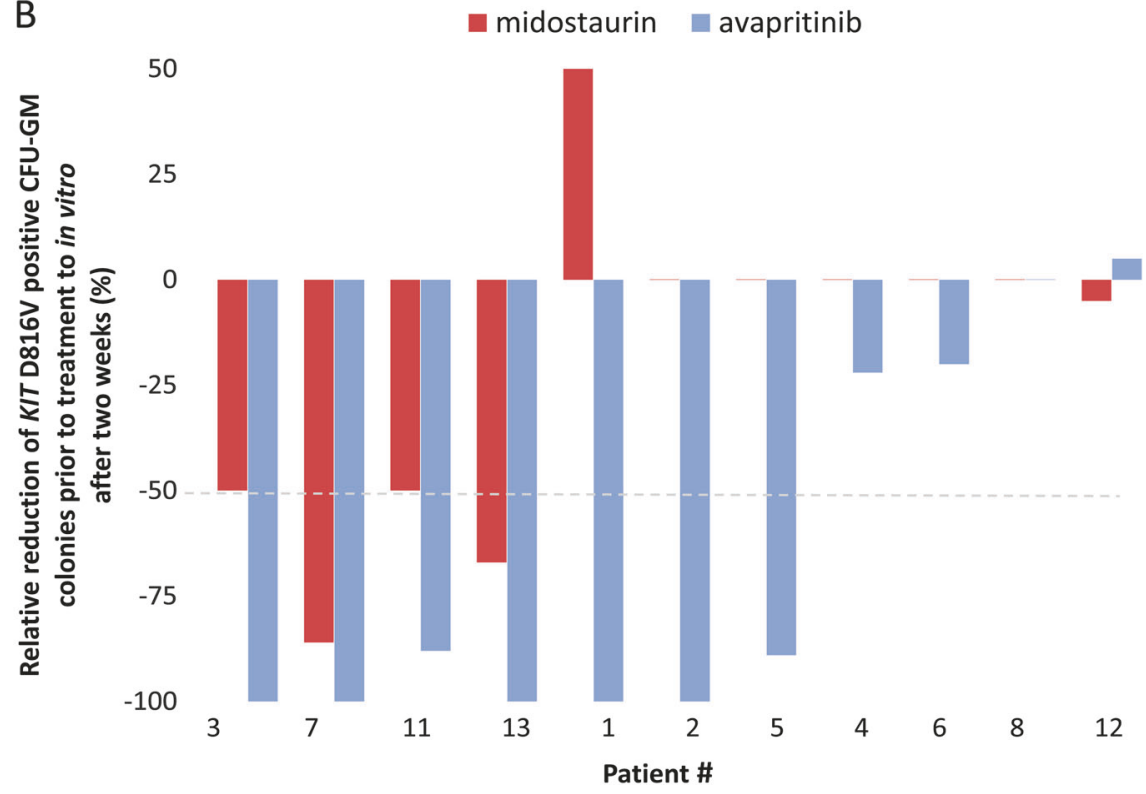

been identified by bulk analysis. Neither midostaurin nor avapritinib had an inhibitory effect in terms of relative reduction of colonies positive for additional somatic mutations (patients \#4: SRSF2, ASXL1, TET2; \#5: SRSF2, IDH2; \#7: SRSF2; \#8: SRSF2, ASXL1, TET2, EZH2; \#9: SRSF2, ASXL1, TET2; \#10: SRSF2, TET2). In addition, longitudinal data on additional somatic mutations were available in five patients after six months in vivo treatment with midostaurin. In patient \#4, a new NPMI mutation emerged after 6 months while in patient \#5 the variant allele frequency of the IDH2 mutation raised from 20 to $49 \%$.

\section{Overall correlation between colony inhibitory assays and clinical/molecular characteristics}

The comparison between colonies obtained prior to treatment and after 6 months treatment of patients $(n=11)$ with midostaurin (in vivo) revealed that $5 / 11(45 \%)$ patients (\#3, $\# 7$, \#9, \#10, \#13, Table 3, Fig. 2a) had a $\geq 50 \%$ reduction of KIT D816V positive colonies. Overall, a significant correlation was observed between the relative reduction of KIT D816V positive colonies in vitro and (a) the relative reduction of KIT D816V positive colonies after 6 months midostaurin in vivo $\left(r=0.8, p<0.017, R^{2}=0.641\right.$, Fig. 3$)$, 
Fig. 3 Correlation between the relative reduction of KIT $\mathrm{D} 816 \mathrm{~V}$ positive single-cell-derived myeloid progenitor cells (CFU$\mathrm{GM}$ colonies, in comparison to proportion of KIT D816V positive colonies obtained prior to treatment) after in vitro incubation with midostaurin ( 2 weeks) and in vivo midostaurin treatment (6 months). CFU-GM, granulocyte-macrophage colony-forming-unit

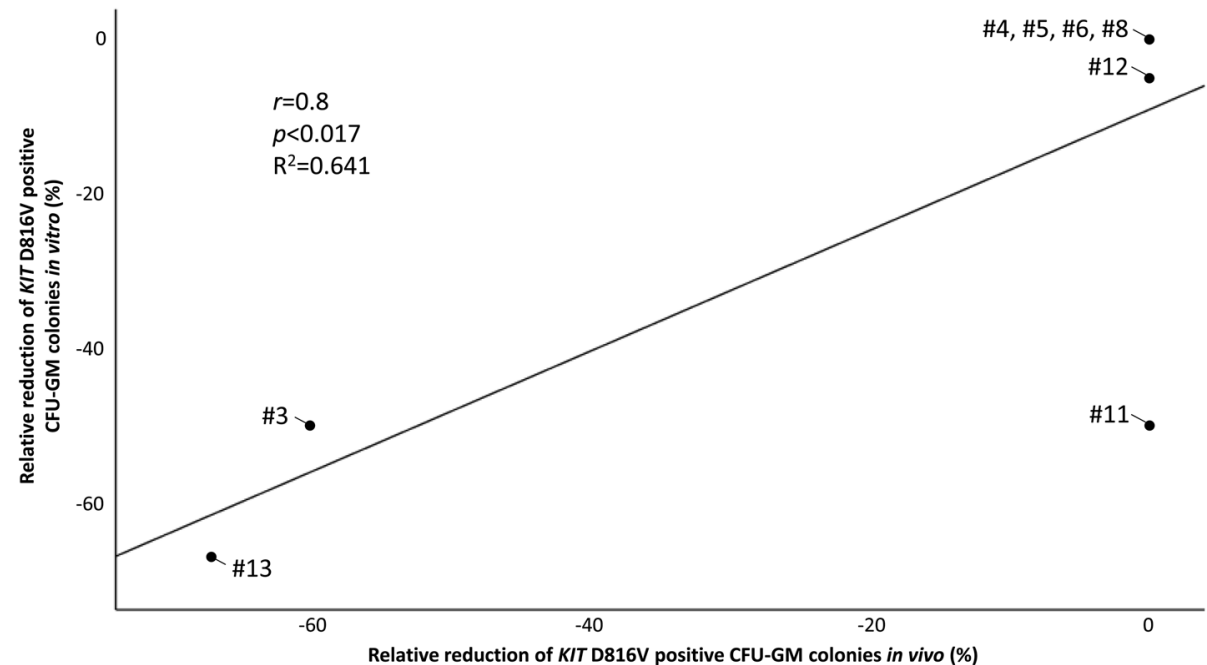

(b) the absence of any mutation in the S/A/R gene panel $(p<0.033)$ and (c) clinical (according to modified Valent response criteria) and molecular (reduction of KIT D816V EAB in peripheral blood $\geq 25 \%, p<0.003$, Tables $4 a, b$ ) response.

\section{Discussion}

In the vast majority of patients with advSM, the KIT D816V mutation is not only present in the mastcell lineage but also in multiple hematopoietic lineages (including the $\mathrm{AHN}$ compartment) [30-32]. The KIT D816V mutation can also be identified in CFU-GM colonies generated from myeloid progenitors [31] and recent data have highlighted the usefulness of these colonies for obtaining a more thorough insight into the clonal architecture of SM and other multimutated myeloid neoplasms [33-39].

In addition to improvement of $\mathrm{C}$-findings, the assessment of responses is based on the relative reduction of mast cell burden, e.g., mast cell infiltration in bone marrow and serum tryptase $[20,40]$. However, this approach may not be sufficient to assess response in the non-mast cell (AHN) compartment of SM-AHN. In this respect, recent data have highlighted the importance and potential superiority of changes of the KIT D816V EAB as it represents in fact both compartments [41]. We therefore sought to assess the inhibitory effects of midostaurin and avapritinib on primary myeloid progenitor cells derived from KIT D816V positive advSM patients.

After two weeks incubation with midostaurin and avapritinib in vitro, the relative reduction of KIT D816V colonies was superior on avapritinib, including number of patients and depth of response. Of interest, three midostaurin non-responders had a significant response to avapritinib, while four avapritinib non-responders showed
Table 4a Correlation between response according to KIT D816V expressed allele burden and response to midostaurin in vitro

\begin{tabular}{lllll}
\hline & & $\begin{array}{l}\text { Response to } \\
\text { midostaurin } \\
\text { in vitro }, \mathrm{c}\end{array}$ & All \\
\cline { 2 - 4 } & & No & Yes & \\
\hline Response according to & No & 6 & 1 & 7 \\
KIT D816V EAB in PB ${ }^{\mathrm{a}}$ & Yes & 0 & 5 & 5 \\
& All & 6 & 6 & 12 \\
\hline
\end{tabular}

$E A B$ expressed allele burden, $P B$ peripheral blood

${ }^{\text {a }}$ Response defined as reduction of the KIT D816V EAB in PB $\geq 25 \%$ after six months [20]

${ }^{\mathrm{b}}$ Response defined as reduction of KIT D816V positive colonies $\geq$ $50 \%$ after two weeks in vitro

${ }^{\mathrm{c}}$ In three cases, in vivo data was used for statistical analysis because in vitro data was not available

Table 4b Correlation between expected response according to mutation(s) in the SRSF2, ASXL1, and RUNX1 (S/A/R) gene panel and response to midostaurin in vitro

\begin{tabular}{lllll}
\hline & & $\begin{array}{l}\text { Response to } \\
\text { midostaurin } \\
\text { in vitro }\end{array}$ & All \\
\cline { 2 - 4 } & & No & Yes & \\
\hline S/A/R mutational status & 0 & 0 & 3 & 3 \\
& $\geq 1$ & 7 & 3 & 10 \\
& All & 7 & 6 & 13
\end{tabular}

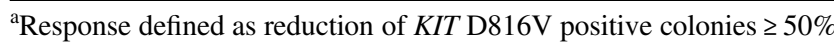
after two weeks in vitro

${ }^{\mathrm{b}}$ In three cases in vivo data was used for statistical analysis because in vitro data was not available

neither a response on midostaurin. These four patients were characterized by a relatively low mast cell burden with regard to mast cell infiltration in bone marrow histology and 
serum tryptase level but a very high KIT D816V EAB (representing disease burden of both SM and AHN) and a poor-prognostic molecular risk profile with $\geq 2$ mutations in the S/A/R gene panel. This data indicates that the KIT $\mathrm{D} 816 \mathrm{~V}$ EAB as marker for overall disease burden and the presence of additional somatic mutations in the S/A/R gene panel may be more important for prediction of response and resistance as the pure mast cell burden (Tables 1 and 3, Fig. 2a, b).

The efficacy and safety of the highly selective KIT -inhibitor avapritinib in patients with advSM is currently being evaluated in an open-label, single-arm phase 2 study (NCT03580655). In an initial dose-escalation phase 1 study (NCT02561988), avapritinib demonstrated an ORR of $83 \%$ per IWG-MRT \& ECNM consensus criteria in 29 evaluable patients. Consistent with our in vitro data, a therapeutic benefit of avapritinib was also observed in several patients with primary or secondary resistance on midostaurin [21, 22, 24, 42].

On midostaurin, the relative reduction of KIT D816V positive colonies after two weeks incubation in vitro was fully paralleled by the relative reduction of KIT D $816 \mathrm{~V}$ positive colonies after 6 months therapeutic treatment (Fig. 3) and by the pattern of clinical response and resistance (Table 3). The in vitro responses were strongly associated with absence of mutations in the S/A/R gene panel $(p<0.033)$ and reduction of the KIT D816V EAB $\geq$ $25 \%$ at month six $(p<0.003)$, parameters which were recently reported to be most predictive for response to treatment and favorable outcome (Tables $4 \mathrm{a}, \mathrm{b}$ ) [41]. This data therefore proves the hypothesis that midostaurin is not only able to target the mast cell compartment but also the KIT D816V positive AHN.

Disparate mechanisms may confer to resistance to midostaurin and avapritinib. We recently revealed the negative impact of mutations in the S/A/R gene panel on phenotype, response rates, resistance, early or late progression and consequently survival in midostaurin-treated patients suggesting primary resistance and/or outgrowth of a multimutated and clinically aggressive KIT D816V positive clone $[9,15,41]$. We now could also demonstrate that neither midostaurin nor avapritinib had an effect on the multimutated KIT D816V negative compartment, which may lead to KIT independent resistance and progression, e.g., secondary KIT D816 negative acute myeloid leukemia [43]. Other potential mechanisms of resistance to midostaurin and avapritinib may be unveiled in ongoing and upcoming clinical trials.

In conclusion, midostaurin is not only able to target the mast cell compartment but also the KIT D816V positive AHN while it may not overcome the adverse effect of high molecular risk mutations (S/A/R gene panel). The in vitro inhibition assay could be considered as a prognostic tool to predict the in vivo response to midostaurin (and potentially also to avapritinib) in patients with advSM. The highly selective KIT -inhibitor avapritinib has significant in vitro activity against KIT D816V, even in midostaurin non-responders. It will therefore be most interesting to extend this exploratory analysis to a larger cohort of midostaurin-treated patients but also to avapritinib-treated patients with or without prior midostaurin treatment. This assay may then help to determine the choice and sequence of available treatment options, e.g., in terms of the potential sequential use of KIT-inhibitors and alternative treatment options in non-responders including (intensive) chemotherapy and potentially early allogeneic stem cell transplantation $[4,5,20,44]$.

Acknowledgements This work was supported by the 'Deutsche José Carreras Leukämie-Stiftung ' (grant no. DJCLS 01R/2018) and by the SEED program of the Mannheim Medical Faculty, Heidelberg University. The technical advice by Susanne Brendel is acknowledged. Karl Sotlar and Hans-Peter Horny are acknowledged for histological diagnosis and the Munich Leukemia Laboratory (MLL) for NGS diagnostics.

Author contributions JL, NN, SK, JS, AF and MJ performed the laboratory work for the study. W-KH, AF, AR and MJ provided patient material and information. EE, AG and $\mathrm{CL}$ provided medication (avapritinib). JL, NN, SK, JS, AF, NCPC, AR and MJ wrote the paper.

\section{Compliance with ethical standards}

Conflict of interest Blueprint Medicines provided avapritinib. EE, AG, and $\mathrm{CL}$ are/were employees of Blueprint Medicines. The remaining authors declare that they have no conflict of interest.

Publisher's note: Springer Nature remains neutral with regard to jurisdictional claims in published maps and institutional affiliations.

Open Access This article is licensed under a Creative Commons Attribution 4.0 International License, which permits use, sharing, adaptation, distribution and reproduction in any medium or format, as long as you give appropriate credit to the original author(s) and the source, provide a link to the Creative Commons license, and indicate if changes were made. The images or other third party material in this article are included in the article's Creative Commons license, unless indicated otherwise in a credit line to the material. If material is not included in the article's Creative Commons license and your intended use is not permitted by statutory regulation or exceeds the permitted use, you will need to obtain permission directly from the copyright holder. To view a copy of this license, visit http://creativecommons. org/licenses/by/4.0/.

\section{References}

1. Arber DA, Orazi A, Hasserjian R, Thiele J, Borowitz MJ, Le Beau MM, et al. The 2016 revision to the World Health Organization classification of myeloid neoplasms and acute leukemia. Blood. 2016;127:2391-405.

2. Pardanani A. Systemic mastocytosis in adults: 2017 update on diagnosis, risk stratification and management. Am J Hematol. 2016;91:1146-59. 
3. Valent P, Akin C, Sperr WR, Escribano L, Arock M, Horny HP, et al. Aggressive systemic mastocytosis and related mast cell disorders: current treatment options and proposed response criteria. Leuk Res. 2003;27:635-41.

4. Scherber RM, Borate U. How we diagnose and treat systemic mastocytosis in adults. Br J Haematol. 2018;180:11-23.

5. Valent $P$, Akin C, Hartmann K, Nilsson G, Reiter A, Hermine O, et al. Advances in the classification and treatment of mastocytosis: current status and outlook toward the future. Cancer Res. 2017;77: 1261-70.

6. Valent $\mathrm{P}$, Akin $\mathrm{C}$, Escribano L, Födinger M, Hartmann K, Brockow K, et al. Standards and standardization in mastocytosis: Consensus Statements on Diagnostics, Treatment Recommendations and Response Criteria. Eur J Clin Invest. 2007;37:435-53.

7. Valent P, Akin C, Sperr WR, Horny HP, Arock M, Lechner K, et al. Diagnosis and treatment of systemic mastocytosis: state of the art. Br J Haematol. 2003;122:695-717.

8. Lim KH, Tefferi A, Lasho TL, Finke C, Patnaik M, Butterfield JH, et al. Systemic mastocytosis in 342 consecutive adults: survival studies and prognostic factors. Blood. 2009;113:5727-36.

9. Jawhar M, Schwaab J, Hausmann D, Clemens J, Naumann N, Henzler T, et al. Splenomegaly, elevated alkaline phosphatase and mutations in the SRSF2/ASXL1/RUNX1 gene panel are strong adverse prognostic markers in patients with systemic mastocytosis. Leukemia. 2016;30:2342-50.

10. Jawhar M, Schwaab J, Schnittger S, Meggendorfer M, Pfirrmann $\mathrm{M}$, Sotlar K, et al. Additional mutations in SRSF2, ASXL1 and/or RUNX1 identify a high-risk group of patients with KIT D816V (+) advanced systemic mastocytosis. Leukemia. 2016;30:136-43.

11. Jawhar M, Schwaab J, Naumann N, Metzgeroth G, Horny HP, Sotlar K, et al. A New Prognostic Score for Advanced Systemic Mastocytosis Based on Clinical and Genetic Characteristics of 210 Consecutive Patients. [Oral Abstract]. In press 2018.

12. Jawhar M, Schwaab J, Meggendorfer M, Naumann N, Horny HP, Sotlar K, et al. The clinical and molecular diversity of mast cell leukemia with or without associated hematologic neoplasm. Haematologica. 2017;102:1035-43.

13. Kristensen T, Vestergaard H, Moller MB. Improved detection of the KIT D816V mutation in patients with systemic mastocytosis using a quantitative and highly sensitive real-time qPCR assay. J Mol Diagn. 2011;13:180-8.

14. Erben P, Schwaab J, Metzgeroth G, Horny HP, Jawhar M, Sotlar $\mathrm{K}$, et al. The KIT D816V expressed allele burden for diagnosis and disease monitoring of systemic mastocytosis. Ann Hematol. 2014;93:81-8.

15. Schwaab J, Schnittger S, Sotlar K, Walz C, Fabarius A, Pfirrmann $\mathrm{M}$, et al. Comprehensive mutational profiling in advanced systemic mastocytosis. Blood. 2013;122:2460-6.

16. Bibi S, Langenfeld F, Jeanningros S, Brenet F, Soucie E, Hermine $\mathrm{O}$, et al. Molecular defects in mastocytosis: KIT and beyond KIT. Immunol Allergy Clin North Am. 2014;34:239-62.

17. Traina F, Visconte V, Jankowska AM, Makishima H, O'Keefe CL, Elson P, et al. Single nucleotide polymorphism array lesions, TET2, DNMT3A, ASXL1 and CBL mutations are present in systemic mastocytosis. PLoS ONE. 2012;7:e43090.

18. Soucie E, Hanssens K, Mercher T, Georgin-Lavialle S, Damaj G, Livideanu $\mathrm{C}$, et al. In aggressive forms of mastocytosis, TET2 loss cooperates with c-KITD816V to transform mast cells. Blood. 2012;120:4846-9.

19. Naumann N, Jawhar M, Schwaab J, Kluger S, Lubke J, Metzgeroth $\mathrm{G}$, et al. Incidence and prognostic impact of cytogenetic aberrations in patients with systemic mastocytosis. Genes Chromosomes Cancer. 2018;57:252-9.

20. Gotlib J, Kluin-Nelemans HC, George TI, Akin C, Sotlar K, Hermine $\mathrm{O}$, et al. Efficacy and safety of midostaurin in advanced systemic mastocytosis. N Engl J Med. 2016;374:2530-41.
21. Evans EK, Gardino AK, Kim JL, Hodous BL, Shutes A, Davis A, et al. A precision therapy against cancers driven by KIT/PDGFRA mutations. Sci Transl Med. 2017;9:eaao1690.

22. Drummond MW, DeAngelo DJ, Deininger MW, Radia D, Quiery AT, Hexner EO, et al. Preliminary safety and clinical activity in a phase 1 study of Blu-285, a potent, highly-selective inhibitor of KIT D816V in advanced systemic mastocytosis (SM). Blood. 2016;128:477.

23. Rose S. Rapid Responses to Avapritinib (BLU-285) in Mastocytosis. Cancer Discov. 2018;8:133.

24. DeAngelo DJ, Quiery AT, Radia D, Drummond MW, Gotlib JR, Hexner E, et al. Clinical activity in a Phase 1 study of BLU-285, a potent, highly-selective inhibitor of KIT D816V in advanced systemic mastocytosis. American Society of Hematology Annual Meeting, Atlanta. 2017.

25. Evans E, Gardino A, Hodous B, Davis A, Zhu J, Kohl NE, et al. Blu-285, a Potent and Selective Inhibitor for Hematologic Malignancies with KIT Exon 17 Mutations. Blood. 2015;126:568.

26. de Melo Campos P, Machado-Neto JA, Scopim-Ribeiro R, Visconte V, Tabarroki A, Duarte AS, et al. Familial systemic mastocytosis with germline KIT K509I mutation is sensitive to treatment with imatinib, dasatinib and PKC412. Leuk Res. 2014;38:1245-51.

27. Gleixner KV, Mayerhofer M, Aichberger KJ, Derdak S, Sonneck $\mathrm{K}$, Bohm A, et al. PKC412 inhibits in vitro growth of neoplastic human mast cells expressing the D816V-mutated variant of KIT: comparison with AMN107, imatinib, and cladribine (2CdA) and evaluation of cooperative drug effects. Blood. 2006;107:752-9.

28. Schoch C, Schnittger S, Bursch S, Gerstner D, Hochhaus A, Berger U, et al. Comparison of chromosome banding analysis, interphase- and hypermetaphase-FISH, qualitative and quantitative PCR for diagnosis and for follow-up in chronic myeloid leukemia: a study on 350 cases. Leukemia. 2002;16:53-9.

29. McGowan-Jordan J, Simons A, Schmid M. ISCN 2016. An International System for Human Cytogenetic Nomenclature (2016): S. Karger Ag; 2016 05/16. 140 p.

30. Sotlar K, Colak S, Bache A, Berezowska S, Krokowski M, Bultmann B, et al. Variable presence of KITD816V in clonal haematological non-mast cell lineage diseases associated with systemic mastocytosis (SM-AHNMD). J Pathol. 2010;220: 586-95.

31. Jawhar M, Schwaab J, Schnittger S, Sotlar K, Horny HP, Metzgeroth $\mathrm{G}$, et al. Molecular profiling of myeloid progenitor cells in multi-mutated advanced systemic mastocytosis identifies KIT D816V as a distinct and late event. Leukemia. 2015;29:1115-22.

32. Wang SA, Hutchinson L, Tang G, Chen SS, Miron PM, Huh YO, et al. Systemic mastocytosis with associated clonal hematological non-mast cell lineage disease: clinical significance and comparison of chomosomal abnormalities in SM and AHNMD components. Am J Hematol. 2013;88:219-24.

33. Lundberg P, Karow A, Nienhold R, Looser R, Hao-Shen H, Nissen I, et al. Clonal evolution and clinical correlates of somatic mutations in myeloproliferative neoplasms. Blood. 2014;123: 2220-8.

34. Hou Y, Song L, Zhu P, Zhang B, Tao Y, Xu X, et al. Single-cell exome sequencing and monoclonal evolution of a JAK2-negative myeloproliferative neoplasm. Cell . 2012;148:873-85.

35. Jan M, Snyder TM, Corces-Zimmerman MR, Vyas P, Weissman IL, Quake SR, et al. Clonal evolution of preleukemic hematopoietic stem cells precedes human acute myeloid leukemia. Sci Transl Med. 2012;4:149ra18.

36. Landau DA, Carter SL, Stojanov P, McKenna A, Stevenson K, Lawrence MS, et al. Evolution and impact of subclonal mutations in chronic lymphocytic leukemia. Cell. 2013;152:714-26.

37. Melchor L, Brioli A, Wardell CP, Murison A, Potter NE, Kaiser MF, et al. Single-cell genetic analysis reveals the composition of 
initiating clones and phylogenetic patterns of branching and parallel evolution in myeloma. Leukemia. 2014;28:1705-15.

38. Papaemmanuil E, Gerstung M, Malcovati L, Tauro S, Gundem G, Van Loo P, et al. Clinical and biological implications of driver mutations in myelodysplastic syndromes. Blood. 2013;122:3616-27.

39. Bendall SC, Nolan GP. From single cells to deep phenotypes in cancer. Nat Biotechnol. 2012;30:639-47.

40. DeAngelo DJ, George TI, Linder A, Langford C, Perkins C, Ma J, et al. Efficacy and safety of midostaurin in patients with advanced systemic mastocytosis: 10-year median follow-up of a phase II trial. Leukemia. 2018;32:470-8.

41. Jawhar M, Schwaab J, Naumann N, Horny HP, Sotlar K, Haferlach $\mathrm{T}$, et al. Response and progression on midostaurin in advanced systemic mastocytosis: KIT D816V and other molecular markers. Blood. 2017;130:137-45.
42. Gotlib J, Radia D, DeAngelo DJ, Prithviraj B, Drummond MW, Hexner E, et al. Avapritinib, a Potent and Selective Inhibitor of KIT D816V, Improves Symptoms of Advanced Systemic Mastocytosis (AdvSM): Analyses of Patient Reported Outcomes (PROs) from the Phase 1 (EXPLORER) Study Using the (AdvSM) Symptom Assessment Form (AdvSM-SAF), a New PRO Questionnaire for (AdvSM). [Oral Abstract]. In press 2018.

43. Jawhar M, Dohner K, Kreil S, Schwaab J, Shoumariyeh K, Meggendorfer M, et al. KIT D816 mutated/CBF-negative acute myeloid leukemia: a poor-risk subtype associated with systemic mastocytosis. Leukemia. 2019. https://doi.org/10.1038/s41375018-0346-z. [Epub ahead of print].

44. Ustun C, Reiter A, Scott BL, Nakamura R, Damaj G, Kreil S, et al. Hematopoietic stem-cell transplantation for advanced systemic mastocytosis. J Clin Oncol. 2014;32:3264-74. 